in truth a relapse, which, slight as were the symptoms, cost me five months of extra treatment. All this trouble was causer by three days of too vigorous tobogganing, and was as purely the re-ult of mechanical strain, not of exposure, as would be the same thing in a tuberculous joint from too free exercise of it. Under the keen super. vision to which I was subjected, however, the bacilli had little chance After a week's rest on a couch I again began to walk very short distances, gradually increasing as I became stronger : and my weight, which had remained stationary during the winter, began to mount up. By the middle of June I was again walking 10 or 12 miles each morning, and in July, 1897, exactly a year after my arrival at Nordrach, I returned to England, where I have resided ever since. My weight on leaving Germany was 13 stones 10 pounds, a gain of three stones."

The striking effect of the treatment in this case is excellently shown by the reproductions of photographs which accompany the article. Now Dr. Walther's sanatorium is not the only one. though it has such a deservedly high reputation; there are many sanatoriums in England, presided over by highly skilled men and women, which are thoroughly trustworthy. Anyone living in England should attempt to be cured under his own climatic conditions, the conditions in which he must eventually live, and these he finds at Nordrach and in his own country. No climate within certain limits matters so long as the air is pure and bracing; no variation in the temperature of the outside air matters so long as it is not absolutely sudden. The most important thing in sanatorium treatment is the character of the man who carries it out. Many so-called sanatoriums both in England and in Europe are conducted on the ba-is of a hotel and do much to bring the treatment into di repute. The first information I want about any particular sanatorium is the character of the man at the head of it and whether he has had practical and thorough teaching in the Nordrach methods. The man in command must be an absolute autocrat and muct be strong enough to send away those patients who do not fulfil his directions in the spirit and in the letter. It is a matter of comparative indifference where the sanatorium is situated, but in my opinion it is folly for English people in whom the disease has made material progress, who are not possessed of ample means and who have to make their living at home. to go to so-called health resorts abroad where they will become accustomed to climatic conditions quite unlike our own and where they have many temptations to stray from the true path of health. Whilst I am on this point I would express my emphatic disapproval of the practice of sending patients in search of health on long sea voyages in steamships unless these are especially adapted for the purpose, as the conditions obtaining here, the stuffy air under deck, the great variations of temperature, and the like, are wholly incompatible with consumptive treatment

How long mu-t patients stay in a sanatorium? It is best that they should remain until all physical signs of active di-ease have gone, until no tubercle bacilli are found in the sputum, and until the inoculation test leads to no result. This happens on the average in from five to six months; it may in some cases take two years or even lunger; whilst in selected cases of men or women who have sufficient character to carry on this treatment for themselves in all its details, two months may be sufficient to train them thoroughly and to place them in a position in which they can look after themselves. When a patient leaves a sanatorium he should be told that for at least two years he must contiuue the treatment as far as possible, that he must avoid all severe strain upon the respiratory or other organs such as bicycling and the like, and shun all places where a large number of people are gathered together, such as theatres, concertrooms, and churches. This is an essential part of the treatment. A man whose disease is fortunately arrested must remember that he is still a weak vessel and liable to further infection or relapse, if he is not careful for some considerable time. He must not cry "the war is over," or he will find that tubercle bacilli, like the Boers, suddenly swoop down from their kopjes, with the result that an unfortunate incident occurs, if not absolute disaster. Patients who have had their disease arrested at a sanatorium are well advised if they have their chests thoroughly examined by a medical man at least once in every three months for several years.

What cases are ineligible for sanat rium treatment? Some sanatorium physicians take any class of case, however severe or apparently hopeless; patients are sent away only when after repeated efforts they cannot eat or when they get the persistent diarrhoea of intestinal tuberculosis. Experience has taught us, however, that in most cases where the amount of disease in both lungs is extensive no great or permanent benefit is obtained by sanatorium treatment and it is little short of cruelty to send such patients, many of whom are obviously dying, long journeys and away from their friends for a form of treaiment which in the nature of things can prolong their life only for a very short time.

One word about drugs. In sanatorium treatment no drugs are used in the routine treatment of the disease, but complications or symptoms such as hæmoptysis, diarrhoea, and constipation are treated on the usual lines. Generally speaking, I may repeat here what I said in a lecture on the treatment of cough in consumption, ${ }^{11}$ the principles which must guide you in giving drugs in this disease are : never give drugs until all other measures have failed, and then never without considering the question whether in treating any particular symptom you are not aggravating the disease either by disturbing the digestive capacity or in some other way.

Well, Mr. President and Gentlemen. I have said enoughand in doing so I am afraid I have strained your patience-to convince you of the pathetic position of one who, like myself, holds these views strongly and who is constantly seeing hospital patients afflicted with consumption. Week after week I see nearly 200 patients who cannot afford the conditions necessary to the successful treatment of their disease. In the majority of instances all $I$ can do is to alleviate the symptoms and trust that, by convincing the patients of the absolute necessity there is for them to do everything in their power to improve their nutrition and general condition they will gradually overcome their disease. In a surprisingly large number-surprising in view of their surroundings-the disease is kept in check and in some cases it is arrested, but in the large majority we can do little more than watch these unfortunate people gradually become worse and die purely from want of money. Take, for example, the case of a man in an advanced stage of consumption working 16 hours a day in an underground bakery in an overheated atmosphere, with six children to support and unable to change his occupation; or that of a billiard-marker in a public-house, always in a smoky and fœetid atmosphere and exposed to constant temptations, what can be done for such cases? Our only answer under present conditions is, "Practically nothing." This, gentlemen, is a national disgrace and in this way the nation is losing every year thousands of lives and large sums of money The only effectual remedy is, as Sir John Burdon Sanderson ${ }^{12}$ has pointed out, the establishment of national sanatoriums on some insurance basia, such as is being done with success in Germany, combined with compulsory notification-not isolation-of tuberculous cases. We can only arrive at this by gradually educating public opinion to such a pitch that the legislature will be compelled to move in the matter, and it is for you, and such as you, to do all that lies in vour power in your practice hereafter to carry conviction on this question to the minds of everyone with whom you may come into contact.

\section{REMARKS ON THE LTFE-HISTORY OF FILARIA BANCROFTI AND FILARIA IMMITIS.}

By LOUIS W. SAMBON, M.D. NAPLeS.

UNDER the title, "Sul Ciclo Evolutivo della Filaria Bancrofti (Cobbold) e della Filaria Immitis (Leidy)" I ("Remarks on the Life-cycle of Filaria Bancrofti, Cobbold, and Filaria Immitis, Leidy"), Dr. Giovanni Noè describes more fully certain researches on the life-history of filaria immitis which he had already published together with Professor Grassi in the Rendiconti della $\boldsymbol{R}$. Accademia dei Lincei on August 25th, 1900.

Il Edinburgh Medical Journal, 1901.

1 Ricerche fatte nel Laboratorio di Anatomia normale della R. Universitầ di Roma ed in altri Laboratorî Biologici, vol. viii., fascicoli 3 e 4. 
The mention of filaria Bancrofti in the title of Dr. Noè's paper is not on account of any new observations made by Professor Grassi or Dr. Noè on the development of this important parasite of mar, as one would naturally imagine, but, apparently, only to enhance the value of the paper. In fact, Dr. Noè introduces his work with the following preface: "The subject I have been studying, under Professor Grassi's guidance, is certain'y one of the most important problems that medical science has ever submitted to the investigations of zoology, because the presence of blood-filariæ in the body of man gives rise to fearful and incurable diseases against which all attempts at an efficient prophylaxis have hitherto been vain, for the mode of entrance of these nematodes into the human body was unknown. The Italian discovery now at last enables us to place the prophylaxis of filariasis on a solid base, indicating the mechanical prevention of mosquitobites, suggested by malaria prophylaxis, as the best means of protecting man from this terrible scourge of tropical cuuntries."

Dr. Noè's assertion that the mosquito propagation of filariasis has been discovered by Professor Grassi and himself or is an "Italian discovery," as he puts it, is, to say the least, surprising, and Professor Grassi should be the very last man to claim, on the analogy of filaria immitis, the merit of having established a scientific basis for the prophylaxis of filaria Bancrofti, seeing that he denied to Major $\mathbf{R}$. Ross similar claims for the establishment of the scientific prophylaxis of malaria on the contention that Ross had only definitely proved the mosquito propagation of Hæmamoeba relicta, a parasite of birds.

In a short historical sketch of the progress of investigations on the life-history of filaria Bancrofti, Dr. Noè mentions how Dr. P. Manson discovered in 1877 that certain mosquitoes acted as intermediary hosts to filaria Bancrofti, and he rightly ascribes Dr. Manson's hy pothesis with regard to the conveyance of the metamorphosed larvæ to man to the erroneous notions entertained at that time by zoologists on the life-habits of mosquitoes. He also reports $T$. L. Bancroft's suggestion, made in 1889 , as to the possibie propagation of filariasis either by the ingestion of infected mosquitoes or through the instrumentality of their puncture. He takes opportunity to ascribe, again incorrectly, to Professor Grassi the discovery of the mosquito propagation of the malarial parasites of man and states that the researches of Major R. Ross on the transmission of hæmamoba relicta did not preclude the propagation of the parasites by means of air and water. Then he refers to a visit which Dr. Manson and I paid to Professor Grassi in 1900 , but the purport of that visit is misrepresented both in Dr. Noè's paper and in the previous publication by Professor Grassi and Dr. Noè.

Firstly, Dr. Manson went to Rome to investigate on the possibility of carrying out a double experiment on the etiology and prophylaxis of malaria in the Roman Campagna; and, in fact, the experiment was successfully carried out by myself and Dr. G. C. Low on the following epidemic season. Secondly, Professor Grassi did not discover in Dr. Manson's specimens a filaria at its maximum stage of development within the head section of a mosquito and did not formulate thereat the hypothesis of the possible transmission of filariæe by means of mosquito-bites for the simple reason that Dr. Manson purposely brought his specimens from London to show Professor Grassi and others that filaria Bancrofti, after having reached a certain stage of development, migrated from the thoracic muscles of its intermediary host, most probably to reach the mouth parts of the insect and to be inoculated to the human definitive host during puncture, as is the case with the malaria parasites. The same specimens had been shown previously to the Fellows of the Royal Society in London; to Professor Blanchard in Paris ; and to Professor Celli, Professor Marchiafava, Professor Dionisi, Professor Bignami, Professor Bastianelli, Dr. Plehn, and Dr. G S. Brock in Rome. Dr. Noè states that Professor Grassi, lecturing in the following March on comparative anatomy in the University of Rome, mentioned the possibility of the transmission of certain filariæ by means of the bite of infected mosquitoes, but I fail to see the bearing of this remark on the claims of priority advanced by Professor Grassi and Dr. Noè Soon after Major Ross's discovery of the mode of transmission of the hamamobidx everyone at all conversant with the study of filariasis at once grasped the possible analogy. If mere statements of opinion were of any scientific value, I might well claim priority, because in an article on Ticks and Tick Fever, published in the Jutrral of 1ropical Medicine in April, 1900, I stated quite positively that filaria Bancrofti was inoculated to man by infected mo:quitoes. That statement was the expression of a firm conviction based chiefly un Dr. Manson's observations and on the analogy of the malaria hæmocytozoa, but it was prematue and therefore regrettable.

During the visit afurementioner, Professor Grassi stated that he had found a filaria, so tar undetermined, within the Malpighian tubes of anopheles maculipennis and, of course, he agreed with Dr. Manson on the possible transmission of these nematodes by means of the bite of their intermediary hosts. Next, a letter from Dr. Manson to Professor Grassi, announcing the finding of filaria $B$ ancrofti between the labium and the mandibles in sections of artificially-infected mosquitoes, is dismissed with the most uncalled-for remark that Dr. Manson, the foremost authority on filariæ, had probably mistaken other nematodes for filariæ. However, says Dr. Noè, even allowing the correctness of Dr. Manson's observations, they do not prove the direct inoculation of filariæ from mosquito to man, because " the mosquitoes might deposit the filaria larvæ in the water while resting on its surface to drink or lay their eggs." Lastly, Dr. Noè discusses Dr. Low's paper on the result of sections made for Dr. Manson of artificially infected mosquitoes received from Bancroft and he accuses Dr. Low of having erroneously supposed the labium to be closed at its base while it is really a continuation of the lacunoma. From an examination of the drawings illustrating Dr. Low's paper Dr. Noè maintains that the filariæ described by Dr. Low as free were still inclosed within the labium, and he adds: "The filarim have no perforating organ and are therefore unable to pierce the tough chitinous case of the labium." He further attempts to prove that both Dr. Manson and Dr. Low were very uncertain about the mosquito inoculation of filaria Bancrofti because Dr. Low entitled his paper "Probable Mode of Infection," and because Dr. Manson, in an article published in the British Medical Journal on Sept. 1st, 1900, says: "The subject of filariasis is by no means worked out," and remarks that "the filaria may leave their insect host by some other channel than the proboscis."

Having thus settled to his own satisfaction that nothing was proved as to the transmission of filariæ from intermediary to definitive host previously to his own researches and to those of Professor Grassi, Dr. Noè passes to consider the history of filaria immitis. He mentions that Calandruccio, in 1892, discovered certain filariæ in the stomach of a mosquito and supposed them to be the larvæ of filaria immitis becau-e, having examined the domestic animals kept in the house where the infected mosquito was captured, Calandruccio found a dog the blood of which was swarming with embryos of filaria immitis, but Dr. Noè considers Calandruccio's discovery as null because Calandruccio was unable at the time to make any further investigation on the subject and because he did not identify the mosquito which he had dissected.

In the following chapter we are told how Professor Grassi discovered that anopheles maculipennis is the usual intermediary host of filaria immitis in Italy. Of course this discovery was neither prompted by Calandruccio's observation nor suggested by Dr. Manson's work on the life-history of filaria Bancrofti, but was the outcome of philosophical reasoning. Professor Grassi, while studying the mosquito-cycle of the hæmamœbidæ, discovered the larvæ of a nematode in anopheles maculipennis. Some time vreviously Professor Grassi had discovered that the distribution of filaria immitis in dogs coincided with the distribution of malaria. Later he discovered that the distribution of anopheles maculipennis coincided exactly with that of malaria, therefore he concluded that the larval nematode found in anopheles maculipennis must be the early form of filaria immitis.

Everybody knows now full well that the distribution of anopheles maculipennis does not coincide with that of malaria. There are many places, even in Italy, without malaria where anopheles maculipennis abounds and there are vast malarial regions where anopheles maculipennis is unknown. The same may be said of the distributional coincidence of filaria immitis and malaria. Moreover, anopheles maculipennis is not the only mosquito capable of fostering the larval stage of filaria immitis. Dr. Noè himself found that in the neighbourhood of Rome anopheles pseudopictus, anopheles bifurcatus, and anopheles superpictus are just as easily infected and he found several gnats 
of the genus Culex (culex penicillaris, culex malariæ) equally susceptible. However, whether guided by Calandruccio's indefinite observation or by erroneous conceptions of the distribution of anopheles maculipennis, of filaria immitis, and of malaria, it is a fact that Professor Grassi and Dr. Noè have experimentally proved that anopheles maculipennis can foster the larval stage of filaria immitis.

Now, let us examine the experiments made by Dr. Noè to prove the inoculation theory of filaria immitis. To obtain infected mosquitoes Dr. Noè began by collecting at random female anopheles in any malarious locality; later be captured his specimens in the houses of Porto di Fiumicino (a small hamlet at the mouth of the Tiber) where, out of 10 dogs, six harboured embryos of filaria immitis. Of the anopheles thus collected at Porto less than 5 per cent. were infected and only about 2 per cent. had fully metamorphosed filłariæ. Finding this proportion totally inadequate, Dr. Noè inclosed two filariated dogs in an ordinary reed hut and liberated in the same large quantities of anopheles gathered in various places. Thus he was able to raise the proportion of infected mosquitoes to about 30 per cent. The mosquitoes that had imbibed blood from the filariated dogs were afterwards kept in special boxes and fed on the juices of various fruit till ready for use. The dogs experimented upon were, so far as could be ascertained from examinations of the blood, free from filarial infection.

On July 19th, 1900, having obtained mosquitoes with filariæ in the labium, Dr. Noè dissected two such insects in normal salt solution and placed the liberated filariæ at the bottom of an incision made in the skin of a dog over a year old in the blood of which filaria embryos had not been found. Sixteen days after the inoculation, the dog was killed, but after a whole day of the most minute researches by Professor Grassi, Dr. Noè, and two other gentlemen, only a small portion of the anterior extremity of an adult nematode was found in the subcutaneous tissue near the genitals. This fragment (three millimetres long) was, however, labeled "filaria immitis" on account of the existence of six papillæ round its mouth and was considered to have been derived from one of the parasites experimentally introduced. On July 20th, a second experiment was made in the same way by stuffing filariæ in a skin wound, but it proved negative.

In consequence of the finding in his first experiment Dr. Noè considered the inoculation theory "sufficiently demonstrated." However, he endeavoured to obtain the inoculation of the parasites in the presumed normal way by means of the bite of infected mosquitoes and thus more befitting experiments followed in which dogs, to all appearances healthy, were inclosed at night with mosquitoes, a small proportion of which possibly harboured filariæ ready to be transmitted. The dogs were muzzled so that they should not swallow the mosquitoes and possibly become infected in this way. At the same time three other dogs were fed on large numbers of mosquitoes gathered in various places or purposely fed on filariated dogs in the laboratory. Moreover, a dog and a puppy were kept for one month at Porto together with the filariated dogs of the locality and in places swarming with mosquitoes. Neither the dogs fed on mosquitoes nor those kept at Porto showed any signs of infection at the necropsy.

The negative result in the dogs kept at Porto Dr. Noè explains by supposing that the dogs did harbour filaria, but that they were killed too soon and that the worms escaped research on account of their diminutive size. The negative result of the feeding experiments, on the other hand, is triumphantly brought forward as "absolutely proving that infection cannot take place through ingestion as suggested by Manson." Why the explanation given in the case of the dogs kept at Porto should not be equally applied in the case of dogs fed on mosquitoes is not quite clear. One of the three dogs subjected to the feeding experiment was killed after eight months, but the other two were killed after one month and two months respectively. And here I must say that Dr. Noè, in stating that Dr. Manson suggested the ingestion theory, is incorrect, because it was Dr. Manson who suggested the inoculation theory and it was through him that the first and most" suggestive evidence was produced. But Dr. Manson has worked at filariæ for more than 20 years and he has acquired that true scientific spirit of caution which seems to be wanting in Dr. Noè. We shall see further how Dr. Manson's reservations are fully ju:tified by the observations of Dr. Noè himself.

The following are the experiments reported by Dr. Noè in which mosquitoes (anopheles maculipennis) supposed to contain fully metamorphosed filariæ were made to bite dogs apparently immune from filarial infection. 1. A bitch bitten on July 19th by two anopheles was killed in Angust; the result was negative. 2. A dog bitten on July 26th and several times after that date by many anopheles; it was killed in October, the result being negative. 3. A dog bitten on August 9th by eight anopheles was killed in October; the result was negative. 4. A dog was bitten on August 23rd and 24 th by anopheles gathered at Porto. On Dec. 5th some few embryonic nematodes were found in its blood and Dr. Noè, mistaking them for the embryos of filaria immitis, supposed them to have been derived from the inoculated filaria and published the experiment as successful. ${ }^{2}$ Early in February, 1901, this dog was killed, bat notwithstanding the most careful researches during four whole days no adult filariæ were found, and Dr. Noè was obliged to suppose that the embryos found in the peripheral circulation of this dog must have been those of some other nematode, possibly those of filaria recondita, a parasite the location of which has, so far, escaped investigation. 5. A dog, two vears old, was bitten on August 23rd and 24th, 1900, by anopheles infected on a filariated dog in the laboratory. Early in the following February embryos similar to those of the previous dog were found in its blood. This dog was killed on April 12th. After a very careful search one immature female filaria immitis was found in the subcutaneous connective tissue. It measured six centimetres, contained no embryos, and to all appearances had not been fertilised. This filaria had evidently nothing to do with the embryos in the blood. Besides, the latter were much smaller than the embryos of filaria immitis, they showed peculiar spring-like movements, and were provided with an erectile spine at the anterior extremity. 6. A small bitch was bitten several times between Oct. 15th and 20th, 1900, by anopheles captured at Porto. It was killed on April 14th, 1901, although no filaria embryos had ever been found in its blood. Nine adult filariæ were found, eight in the connective tissue and one in the pericardium. All were sexually mature. The females had been fertilised and they contained numerous embryos but they had not yet commenced parturition. The longest males measured five centimetres and the longest females 11 centimetres. 7. A dog, bitten in August, 1900, by anopheles collected at random in various localities, was killed on Sept. 3rd, 1901. A female filaria immitis was found in the subcutaneous connective tissue, but the worm had not been fertilised and no embryos of any kind had ever been found in the blood of the host.

Of these seven experiments Nos. $1,2,3$, and 4 were negative, but Nos. 5, 6, and 7 were considered to be positive, because one or more filariæ were found at the necropsy. On account of the last three experiments Dr. Noè concludes: "It is fully demonstrated that the filariæ enter their definite host by means of the bite of mosquitoes." The negative experiments he explains by supposing that the experimentmosquitoes were probably not infected or that the inoculated filarim were not detected at the necropsy of the dogs on account of their diminutive size, the hosts having been killed too soon.

The crudeness of the above-mentioned experiments might be somewhat explained if the experiments had been instituted by Dr. Noè alone, who was at the time only a student, but we are told that they were carried out in Professor Grassi's laboratory and under his tuition, and, indeed, they were first published in the name of both. The methods of the attempts to procure infected mosquitoes and the extraordinary carelessness shown in the choice of suitable dogs, are most surprising, especially in a man who was supposed to have gained some appropriate experience during the researches he made while studying the mosquito propagation of the malaria parasites. The mosquitoes for the experiments should have been reared and infected in the laboratory and the dogs should have been puppies born after the end of the last season of infection (October) and carefully guarded from every possible source of infection till the time of experiment. Instead of which we find Dr. Noè experimenting with non-infected mosquitoes and with dogs, two and more years old, already harbouring various species of filariæe.

Of the two experiments in which filariæ were inserted into skin wounds one is reported as successful and the other as negative. In the experiment considered to have been

2 Rendiconti dell' Accademia dei Lincei, vol. ix., 2. sem., serie 5 , fase. 12 . 
successful only a small fragment of a nematode was found. We are told that it proved sufficient for the identification of the parasite, but I doubt this very much and my doubt is not a retort to the insinuation made by Dr. Noè that perhaps the nematodes described by Dr. Manson were not filariæ, but is very justly based on Dr. Noè's most awkward mistakes. In fact, Dr. Noè owns himself that he mistook the embryos of some other nematodes for those of filaria immitis which he, a zoologist, had been studying for nearly two years; but another very bad mistake is found at page 325 where, after stating that filaria immitis at its maximum stage of development within its intermediary host measures about $900 \mu$, he adds that once he found one that had attained the enormous length of two centimetres. Dr. Noè found this filaria amongst the thoracic muscles of an anopheles and explains its gigantic proportions by its unusual location which "must have caused a long permanency in the body of the mosquito." While in the Roman Campagna Dr. Low and I found similar filariæ in the thoracic muscles of anopheles maculipennis, but time and circumstances prevented us from determining the definitive host of these nematodes. However, the greater dimensions of these parasites and the different location for their development suggest at once a specific distinction.

Even allowing that the identification of the tiny bit of worm was possible and absolutely correct, it is not by any means proved that it was derived from one of the artificially introduced filariæ. It was ascertained that the dog at the time of the experiment had no filaria embryos in its blood, but it was not proved that it did not already harbour young filariæe in its tissues.

In experiment No. 6 of the series, in which anopheles supposed to be infected were made to bite dogs supposed to be non-infected, nine sexually mature filariæ were found six months after the date of supposed infection. In experiment No. 5, a filaria only half grown was found at the post-mortem exarnination eight months after the date of experimental inoculation, and in experiment No. 7 a filaria still immature was found 13 months after experimental inoculation. Supposing for one moment that the immature filaria found in experiment No. 7 had really been derived from one of the larvæ inoculated 13 months previously, it would be difficult to understand how in experiment No. 6 the filariæ could have reached full maturity in less than six months.

From what I have said, it is clear that no account can be taken of Dr. Noè's experiments, but Dr. Noè mentions an observation of a different kind by which he says he obtained quite unexpectedly a most definite proof as to the direct inoculation of filaria by means of the bite of mosquitoes. On July 25th he gathered a large batch of anopheles. On August 5th he examined a number of these mosquitoes and ascertained that some of them were filariated. On the 10th he examined the remaining mosquitoes but did not find a single filaria in any of them. Supposing that the mosquitoes might have lost their filariæ while feeding on fruit he looked for the nematodes in the fruit pulp on which the mosquitoes had fed but was unable to find any. On the 23rd, having found filariæ in the labium of certain mosquitoes out of a large quantity which had been fed on the 10th and 11th of that month on a filariated dog, he closeted some of these mosquitoes all night with a healthy dog (experiment 4 or 5). On the next morning these anopheles were heavily gorged with blood. On dissection he did not find a single filaria in any of them, but he says that he found in their Malpighian tubes lesions undoubtedly significative of filarial infection. $\mathrm{He}$ at once examined the remaining mosquitoes and found that five out of 11 contained filariæ in their labia and showed in their Malpighian tubes changes similar to those of the gnats previously examined. Thereupon Dr. Noè concluded that the anopheles which had bitten the dog must have emptied out their parasites during puncture and that the remaining anopheles of the previous batch. which on August 10th had no filariæ while others of the same batch five days earlier had been found infected, must have emptied their larvæ in the fruit pulp and that the Jiberated filariæ must have escaped detection on account of their very minute size.

This observation is, like the others, most unsatisfactory. We know that only a certain proportion of the mosquitoes employed were infected ; it is quite possible, therefore, that those dissected after biting the dog or feeding on fruit were the non-infected ones. Admitting that those in which Dr. Noè says he found lesions of the Malpighian tubes were really infected it is in no way proved that the filaria were liberated during puncture and not evacuated with the fæces. Dr. Noè was unable to demonstrate the presence of filariæ in the fruit pulp and his experiments upon dogs, as we have already seen, are totally untrustworthy. Against Dr. Noè's surmise as to the liberation of filariæ in fruit during puncture stand the observations of T. L. Bancroft and Dr. Low which prove the contrary. Besides, Dr. Noè himself in another part of his paper says that to obtain the liberation of the filariæ the labium must bend and rupture: "In the case of fruit, when the insect can absorb the juices at the surface without thrusting the stylets to any depth, and therefore without bending sufficiently the labium, the liberation of the parasites does not take place." Then, again, how is it that all the mosquitoes examined had emptied all their filariæ simultaneously while Dr. Noè states that the parasitic larvæ do not reach maturity all simultaneously but successively, and that, therefore, this migration to the mouth parts of the host takes place by "successive stages." "In fact," he says, "I have frequently observed that after an emission of parasites the Malpighian tubes still contain a certain number of filariæ ready to leave in a short lapse of time their larval seat. It is obvious, therefore, that the labium becomes again gradually invaded by, and stuffed with, filariæ and that thus a second emission may take place on a subsequent puncture. Thus the mosquitoes when abundantly infected may have the power of inoculating the parasites two, and perhaps even more, times."

Now, leaving aside Dr. Noè's contradictions and admitting for a moment that, as he believes, the filariæ might escape from their intermediary hosts while the latter imbibe the juices of fruit, we obtain a strong proof of the judiciousness of Dr. Manson's caution in writing that "the fact of the presence of the filaria in the proboscis of the mosquito suggests, without actually proving, that the parasite is directly inoculated into man by mosquito-bite. At the same time we must remember that the fully metamorphosed filaria is sometimes found around the stomach, about the viscera, and elsewhere than in the head of the mosquito. It is quite possible, therefore, that it may leave the insect by some other channel than the proboscis, and it may be passed into water with the fæces, the eggs, or even by the proboscis." Finally, Professor Grassi and Dr. Noè claim to themselves the discovery of the inoculation theory of filariasis because, they say, Dr. Low was not able to prove how the filariæ escaped from the labium. They suggest that the filariated labium tears towards the middle of its dorsal aspect while bending during puncture. But this is nothing more than a hypothesis and Dr. Noè himself says: "I think that an absolute certainty is difficult to obtain on this point because, as everyone understands, one would have to surprise the filariæ in the act of escaping during the operation of the puncture, and this is far from easy." T. Everett Dutton has suggested a far more rational point of escape at the tip of the labium, between the labellæ. This area is covered by a very delicate membrane which tears very easily and is practically over the point of puncture when the mosquito draws blood--a very important condition to insure the inoculation of the liberated filaria. Personally, I believe that the filariæ pass into the wound along the dorsal groove of the hypopharynx, having reached the mouth cavity by piercing the delicate membrane which connects the chitinous pharynx to the base of the hypopharynx, and I believe that their presence within the labium bas no other significancy than that of their presence within the palpi which is just as frequently observed. However this may be, the hypothesis advanced by Professor Grassi and Dr. Noè is certainly the least probable.

I think that it is to be very much regretted that Dr. Noè did not limit his paper to the researches which he made on the development of filaria immitis in anopheles maculipennis. His observations on the structure of this parasite during its larval development are certainly accurate. I do not agree with any of his interpretations, but that is perhaps a matter of opinion. For instance, Dr. Noè thinks that the jutting posterior intestine of the filaria in its early stages becomes an organ of adhesion and fixes the parasite to the cells of the Malpighian tubes. I think instead that it subserves the function of nutrition If we examine the filaria larva between the sixth and ninth day of its development within the Malpighian tubes of a mosquito we find that its posterior intestine does not communicate with the rest of the alimentary apparatus but forms a completely closed, bladder-like body, part of which projects outside the body 
of the worm into the cytoplasm of the host to absorb nutriment and, indeed, the vesicle gradually fills with a clear, transparent fluid. Besides, on the ninth day or thereabouts the chyliferous intestine becomes connected with the posterior intestine and the protruding part of the latter opens to form the anus. 'Thencelorth the filaria feeds by the mouth.

Dr. Noè has ob:erved that the filariæ undergo at times a brown degeneration within the Malpighian tubes of their host and, true to the traditions of the Roman school, he believes this degeneration to be a retrogressive process of the parasite. This so-called brown degeneration begins by scattered brown spots which under a strong magnifying power have a lenticular shape. The spots gradually increase in number and coalesce into large dark-brown patches. These brown bodies may appear on a few or on all the filariæ contained in one or in all of the Malpighian tubes of a mosquito. They are no other than the "black spores" described first by Major Ross in connexion with the hæm amcebidæ. I believe that they represent a parasitic infection comparable to the pebrine disease of silk worms.

Dr. Noè closes his paper with a most extraordinary remark. He recognises that the prodigious fertility of filaria immitis is an admirable adaptation for the perpetuation of the species, but he explains its operation in a way which seems to me to be far more original than reasonable He says that the mosquitoes become so easily infected that if numbers of them did not die the canine species would soon become totally extinct and with the disappearance of dogs the filaria would necessarily also disappear ; therefore, to avoid such a disaster the filariæ have excogitated the admirable means of killing off their necessary intermediary hosts by a prodigious fertility and consequent heavy infection. Dr. Noè explains the passage of the filaria from definitive to intermediary and from intermediary to definitive hosts in a totally passive way and I will not ask him why other filariæ develop in other parts of the mosquito instead of gravitating, like his filaria immitis, first into the Malpighian tubes when the mosquito sits up after its meal, and then into the labium when the latter comes down again head foremost to draw blood, but $I$ feel that I must protest against the stigma of suicidal mania which he casts on the worm, forgetting the universal significancy of an enormous fertility which is common to numberless species, and forgetting that the domestic dog may posibly not be the only definitive host of filaria immitis and that filaria immitis, although widely distributed, is strictly limited to certain swampy stations.

\section{SOME FURTHER STATISTICS REGARDING THE EFFECT OF INOCULATION AGAINST TYPHOID FEVER IN SOUTH AFRICA,}

WITH SPECIAL REGARD TO THE QUESTION OF AGE.

BY ALEXANDER CROMBIE, M.D EDIN., LIEUTEYAN'T-COLONEL, M.M.S. (RETIRED).

IN THE LAxcet of May 3rd, 1902, at p. 1241, will be found the statistics of 250 officers invalided from South Africa for various causes. These figures showed a higher percentage incidence of typhoid fever among the inoculated $(28 \cdot 5)$ than among the non-inoculated $(22 \cdot 0)$, and it was pointed out that this might be due to a higher rate of recoveries among the inoculated. I do not propose to discuss the figures which might be adduced in support or otherwise of this opinion. My figures also showed that the average date of attack after disembarkation in South Africa was shorter among the inoculated ( $9 \cdot 4$ months) than among the non inoculated $(10 \cdot 3$ months), but that the non-inoculated were more : usceptible during the first five months after di-embarkation than the inoculated. The inference to be drawn from the:e figure- was that inoculation conterred a certain meanure of protection for a period of about six montins After that period the inoculated appeared to suffer more than the non inoculater. I hinted that these differences in licated the operation of some law affecting the figures.

The publication of these statistics led to a corre-pondence with Professor Wright of Netley who suggested that the law referred to was probably that of age and susceptibility. He thought it probable that the inoculated would be found to be younger men than the non-inoculated and that the higher incidence among the former after the six months of protection afforded by inoculation had passed was in all likelihood due to the re-assertion of their greater susceptibility on account of their comparative youth. I had not recorded the ages of the 250 officers who furnished the statistics and I accordingly commenced a new series of observations with a view to ascertain what truth there was in Pıfessor Wright's suggestion. 'The following figures are the result of this inquiry. Table 1 . shows that the average age of the inoculated was 25.4 years and that of the non. inoculated was $30 \cdot 6$ years, a difference of five years. The incidence of typhoid fever among the former was 33.3 per cent. and among the latter 329 per cent.

TABLE I.-Showing the Average Age of the Inoculated and Non-inoculated.

\begin{tabular}{|c|c|c|c|c|c|}
\hline 一 & & Number. & $\begin{array}{c}\text { Average } \\
\text { age (years). }\end{array}$ & Cases. & Per cent. \\
\hline $\begin{array}{c}\text { Inoculated once... } \\
,, \quad \text { twice... }\end{array}$ & $\begin{array}{ll}\cdots & \cdots \\
\cdots & \cdots\end{array}$ & $\begin{array}{l}89 \\
13\end{array}$ & $\begin{array}{l}25 \cdot 4 \\
25 \cdot 5\end{array}$ & $\begin{array}{l}24 \\
10\end{array}$ & $\begin{array}{l}26 \cdot 9 \\
76 \cdot 9\end{array}$ \\
\hline Total inoculated & $\ldots \quad \ldots$ & 102 & $25 \cdot 4$ & 34 & $33 \cdot 3$ \\
\hline Previous attacks & $\begin{array}{ll}\ldots & \ldots\end{array}$ & 19 & $32 \cdot 1$ & 3 & $15 \cdot 8$ \\
\hline Not inoculated ... & $\begin{array}{ll}\cdots & \cdots\end{array}$ & 85 & $30 \cdot 6$ & 28 & $32 \cdot 9$ \\
\hline Totals & $\ldots \quad \ldots$ & 206 & $28 \cdot 2$ & 65 & $31 \cdot 5$ \\
\hline
\end{tabular}

The figures in Table I. show a distinct advantage in favour of a single inoculation, but they indicate a strong susceptibility to enteric fever among those who were inoculated twice. In this series 10 out of 13 officers who were inoculated twice on the outward passage contracted typhoid fever after disembarkation in South Africa. In my first series the proportion attacked was smaller, two in 10 . Taking the two series together it will be found that of 23 double inoculations 12 were infected, or over 50 per cent., as against 33 per cent. a moog the non-inoculated. I do not think that a difference of age amounting to five years would accuunt for this greater incidence; and it is possible that the double inoculation is excessive and diminishes the resisting power of the blood to infection. The incidence among those twice inoculated is just double that among the once inoculated, and such a result would not be in discord with some of Professor Wright's more recent experimental work.

In the following tables (Tables II., III., IV., and V.) the incidence in relation to age is shown in detail. They show that 60 per cent. of the inoculated were under 26 years of age, against 22 per cent. among the non-inoculated. The incidence at this age among the non-inoculated was 63.4 per cent. ; among those inoculated once 27.8 per cent. ; and among those inoculated twice 71.4 per cent. This gives a difference of 35 per cent. in favour of a single inoculation at this age, which must be regarded as a very substantial gain. Between the ages of 26 and 35 years the number of inoculated constituted 31 per cent. of the total inoculated, against 50 per cent. among the non-inoculated. At these ages the incidence among 42 non-inoculated was 31 per cent. among $\angle 7$ inoculated once 22 per cent.; and among five inoculated twice 80 per cent. Here there was a gain of 9 per cent. among those inoculated once.

TABLE II.-Inoculated Once.

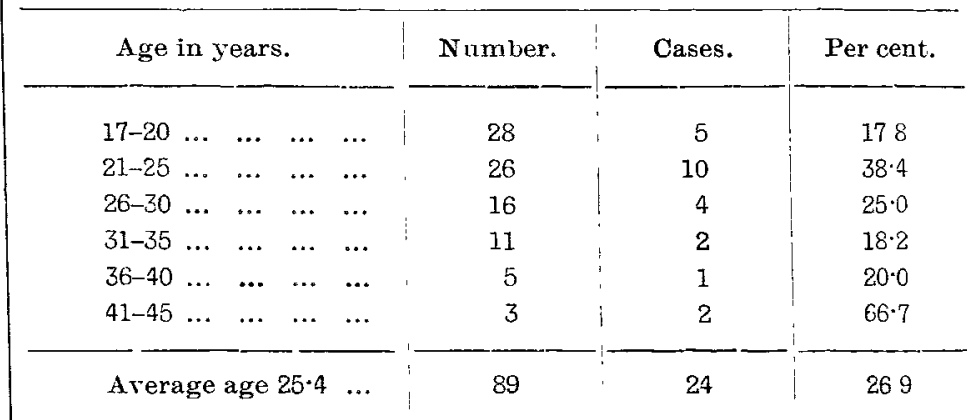

